\title{
CSAI analysis of non-crimp fabric cross-ply laminate manufactured through wet compression molding process
}

\author{
Sooyoung Lee ${ }^{\mathrm{a}}$, Chaeyoung Hong ${ }^{\mathrm{a}}$, Taeseong Choi ${ }^{\mathrm{a}}$, Hye-gyu Kim ${ }^{\mathrm{b}}$, Seong-Woo $\mathrm{Im}^{\mathrm{b}}$, Soo-Chang Kang ${ }^{\mathrm{b}}$, \\ Young-Bin Park ${ }^{\mathrm{a}, \mathrm{b}}$, Wooseok $\mathrm{Ji}^{\mathrm{a}, *}$ \\ ${ }^{a}$ Department of Mechanical Engineering, Ulsan National Institute of Science and Technology (UNIST), Ulsan, South Korea \\ ${ }^{\mathrm{b}}$ UNIST Composites Research Center, Ulsan, South Korea
}

\section{A R T I C L E I N F O}

\section{Keywords:}

Wet compression molding

Non-crimp fabric

Barely visible impact damage

Compressive strength after impact

\begin{abstract}
A B S T R A C T
The main purpose of the present work is to demonstrate mechanical performance of a wet-compressionmolding (WCM) composite product through conventional compressive-strength-after-impact (CSAI) analysis. Biaxial non-crimp fabric (NCF) is utilized to manufacture laminated composite panels. Specimens are cut from the panels and tested to characterize fundamental mechanical properties of the NCF composite. The volume fractions of fibers and voids are also measured to evaluate the quality of the WCM product. Impact tests are carried out to examine impact resistance of the composite structure. Numerous impact characteristics at various energy levels are quantitatively measured. Internal failure patterns and damage extent are revealed via Xray CT. Compression tests on the impacted plates are followed to evaluate structural integrity and damage tolerance (SIDT). 3D DIC technique is employed and distinct buckling responses dependent on impact energy levels are successfully visualized. Experimental results are showing a promising potential of the WCM process as one of the alternatives to the conventional autoclave-based fabrication method.
\end{abstract}

\section{Introduction}

Owing to the recent efforts of the automotive sector, various out-ofautoclave (OOA) processes for the commercial scale production of composite structures are now available. Autoclaves cannot be the first option for automobile manufacturers because of high volume production. They have been interested in composite fabrication processes that can be automated with cycle time in the order of several minutes [1]. Such processes are now being actively developed and implemented in automotive production lines due to an ever-increasing demand for lightweight vehicles to respond to strengthening regulations on fuel consumption and carbon dioxide emissions [2]. Typical OOA manufacturing processes that are currently working in the field are resin transfer molding (RTM), compression molding (CM), injection molding (IM) and so on. The conventional RTM has been further extended to high-pressure RTM (HP-RTM) to produce high-performance lightweight parts [3]. Vacuum-assisted RTM (VARTM) is still widely used in the field due to its low tooling cost, availability for room temperature processing and scalability for large structures [4]. CM has been utilized for composite products based on glass mat-reinforced thermoplastic (GMT) [5] and sheet molding compound (SMC) [6]. WCM is another variation of the CM process [7,8]. IM has been widely used for manufacturing discontinuous fiber-reinforced composite parts [9-11].

Various automobile parts have been produced through the aforementioned processes and other OOA techniques. Leaf springs [12], a hood [13] and a bumper system [14] were fabricated via the VARTM process. Ball et al. utilized the HP-RTM process to manufacture a roof frame [15]. Baskaran et al. compared manufacturing costs of conventional RTM, HP-RTM and compression RTM (CRTM) processes for the production of a roof case [16]. Bartus et al. employed extrusion-compression molding to develop a long fiber thermoplastic (LFT) bus seat [17]. Li et al. studied impact characteristics of GMT body parts manufactured by CM [5]. Structural reaction injection molding (SRIM) process was applied to an integrated car body's frame [18]. BMW group succeeded in commercially implementing WCM, RTM and SMC processes to manufacture automobile frames [19].

Commercial aircraft manufacturers also show growing interest in OOA processes to reduce production cycle and expensive equipment cost. The Boeing Company reported the implementation of RTM for manufacturing circumferential frames and window frames in [20]. Fial

\footnotetext{
* Corresponding author.

E-mail address: wsji@unist.ac.kr (W. Ji).
} 
et al. utilized an automated WCM process with a load-path optimized preform to fabricate an armrest structure [21]. However, their attempts to produce OOA composite structures have been conservatively made due to high standards for process reliability and structural integrity demanded by various airworthiness certifications. The feasibility studies on the OOA production for aerospace applications were mainly concerned with secondary load-bearing structures.

Nowadays, however, owing to the recent development of highly reactive resin systems and robust equipment, several researchers applied the HP-RTM technique to major load-bearing structures for automotive applications. Founded on successful implementation of the OOA process, they reported improved mechanical performances of composite structures fabricated through HP-RTM. Henning and his team performed extensive studies on the effect of various process parameters on the mechanical properties of HP-RTM composites $[22,23]$. In [23], various resin systems were tested to investigate the influence of matrix materials on the mechanical performances of the composite products and their impact damage resistance. They also examined the mechanical and physical properties of HP-Compression RTM (HP-CRTM) products manufactured with different processing parameters such as press forces and resin injection rates [4]. Bodaghi et al. performed a comparative investigation on porosities in composite parts fabricated through autoclave and HP-RTM processes [24]. This study reported that HP-RTM can produce a composite part, of which quality is comparable to that of an autoclave-processed composite; a high fiber volume fraction with a very low void content. Rondina et al. assessed the feasibility of the HP-RTM process to replace the conventional hand lay-up method for manufacturing a composite car wheel based on mechanical and durability testing results [25]. Carbon textile composite specimens were manufactured through HP-RTM under various heat aging conditions. The specimens were tested through short-beam bending, compressive loading and compression after impact (CAI) experiments. Their study demonstrated that the OOA product can exhibit a competent mechanical performance as a substitute of the autoclave-cured composite part. Cherniaev et. al. examined quasi-static properties and strain rate dependent mechanical responses of non-crimp fabric (NCF) composites manufactured using the HP-RTM process [26]. They observed a distinctive strain rate sensitivity of the NCF composite along the transverse direction.

WCM process is another well-known OOA method for manufacturing continuous fiber-reinforced thermosetting composites. Bockelmann investigated the effect of process conditions pertaining to resin flow on the porosity and bending strength of NCF composites manufactured through WCM [27]. Mariano also examined the porosity of NCF composites resulting from various vacuum conditions of the WCM process [28]. Compared to the HP-RTM composites, only few researches have been conducted regarding the mechanical performance of WCM products. In [27] and [28], the mechanical or physical properties were evaluated merely for comparison purposes in a process of establishing optimal manufacturing conditions. In the presented study, compressive strength after impact (CSAI) analysis of a WCM product is carried out to examine its structural integrity and damage tolerance and assess the feasibility of the composite structure as a replacement of metalbased load-bearing structures.

\section{Material characterization}

\subsection{Fabrication of NCF composite panels through WCM}

The NCF composite in the presented study is made of carbon NCF (SIGRATEX, SGL Carbon, Germany) with an epoxy resin system (SCI-S300R/S520H, SHIN-A T\&C, Korea). In the fabrication process, the resin is first pumped into a mixing head at $80{ }^{\circ} \mathrm{C}$ and blended with a hardener and release agent supplied at room temperature. The mixed liquid in the head then flows out through the flat nozzle as shown in
Fig. 1(a). Total 8 biaxial NCF layers are placed on the lower mold with the same orientations before the resin is added. The flat nozzle is connected to a robot arm that is programmed to uniformly spread the liquid resin onto the preform. The resin injection process takes only $12.5 \mathrm{~s}$. Injection rates of the resin, hardener and release agent are set to $48 \mathrm{~g} / \mathrm{s}, 12 \mathrm{~g} / \mathrm{s}$ and $1 \mathrm{~g} / \mathrm{s}$, respectively. After the resin pouring process, the press machine shown in Fig. 1(b) closes the molds with the pressing force of $4000 \mathrm{kN}$. The molds remain closed for $10 \mathrm{~min}$ to cure the resin. The temperatures of the upper and lower molds are maintained at $140{ }^{\circ} \mathrm{C}$. Flat panels are manufactured with the size of $660 \mathrm{~mm} \times 420 \mathrm{~mm}$ and the thickness of $4 \mathrm{~mm}$.

\subsection{Microstructure and volume fractions}

A single sheet of non-crimp fabric (NCF) is typically composed of two unidirectionally continuous fiber reinforced layers that are orthogonally stacked and stitched together. Fig. 2 schematically illustrates the NCF microstructure based on the microscopic observations at different magnification levels as shown in Fig. 3. The yarn widths in the $0^{\circ}$ and $90^{\circ}$ directions are $2.5 \mathrm{~mm}$ and $5 \mathrm{~mm}$, respectively. The two orthogonal yarns are stitched using polyester fibers. In Fig. 3(a), the cross-ply stacking sequence can be observed with the polyester yarns. Fig. 3(b) shows the fibers with their dimensions measured using image processing software.

Volume fractions of the fibers, matrix material and voids in the NCF composite are measured according to ASTM/D3171. Total three specimens with the size of $20.0 \times 20.0 \times 3.8 \mathrm{~mm}^{3}$ are tested to measure the volume fractions and the results are summarized in Table 1 . The average fiber volume fraction is $36.0 \%$ with the average void content of $4.9 \%$. Although the fiber volume fraction is comparably low for typical aerospace applications, the void contents are also low, showing a promising potential of the WCM process to satisfy high quality standards of aerospace structures.

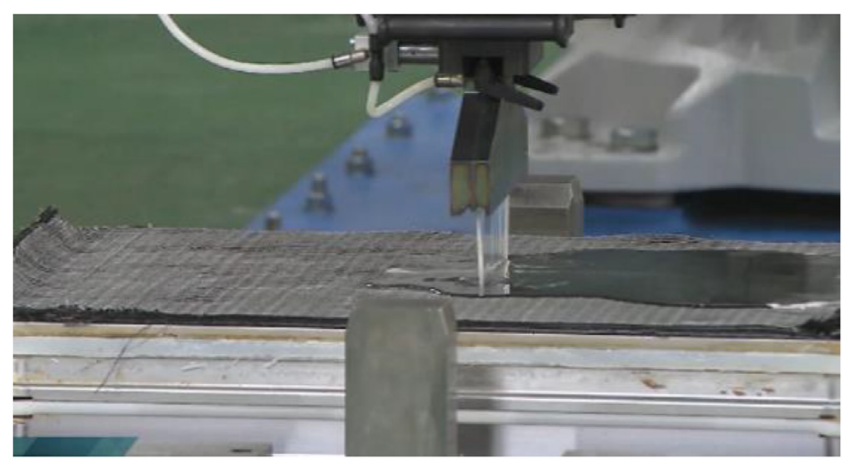

(a)

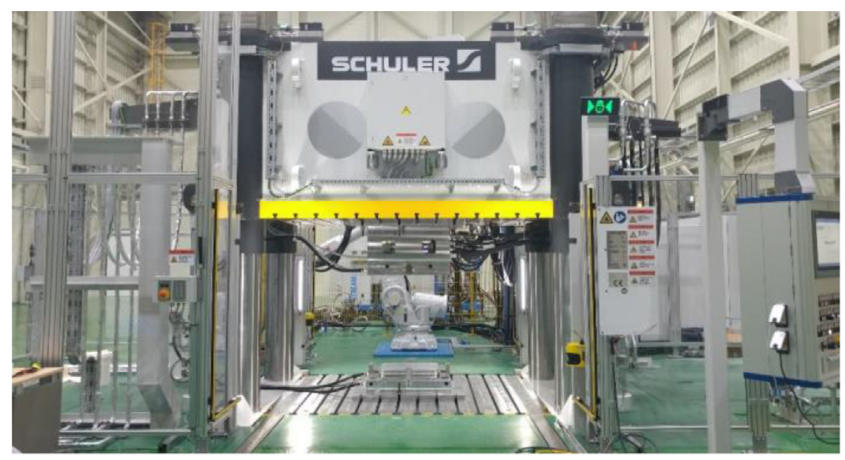

(b)

Fig. 1. (a) WCM process (b) In-house 2500-ton press. 

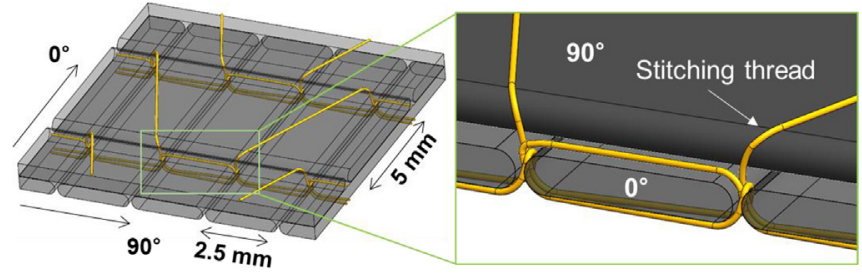

Fig. 2. Schematic illustration of the NCF microstructure.

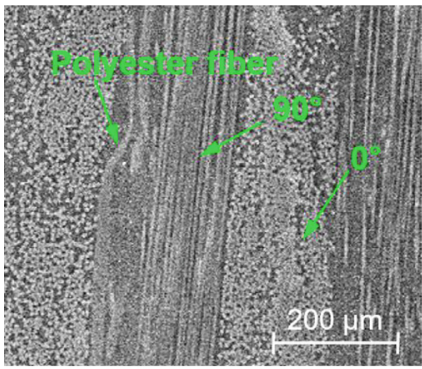

(a)

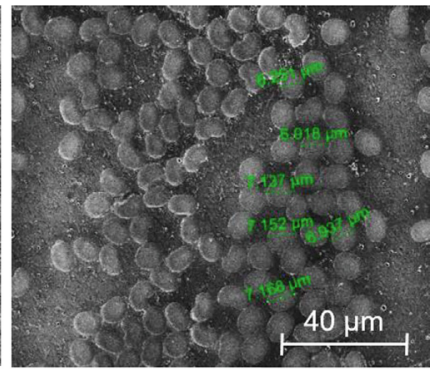

(b)
Fig. 3. Microscopic observation of the NCF composite at different magnification levels.

\subsection{Mechanical properties}

Fig. 4 shows experimental results from tension and shear tests to measure the mechanical properties of the NCF composites. The tensile and shear tests are carried out according to ASTM/D3039 and ASTM/ D3518, respectively. Two specimens are tested for each orientation for the tension tests. Load data are obtained from the load cell installed in a loading frame and an extensometer is used to measure elongation of the specimens. The axial stresses in Fig. 4(a) are defined as the load divided by the initial cross-sectional areas of the specimens. The axial strains are computed by dividing the measured elongation with the gage length. As can be seen in Fig. 4(a), the NCF composite exhibits slightly stiffer and stronger responses in the $0^{\circ}$ direction mainly due to the difference of yarn widths, i.e., different fiber volume fractions between the two directions (see Fig. 3).

The shear stresses and shear strains in Fig. 4(b) are computed by transforming axial and transverse measurements by $45^{\circ}$. The load data is again measured from the load cell of the loading frame. The shear strains are obtained from digital image correlation (DIC) analysis. In Fig. 4(b), a typical configuration of the specimens with a speckle pattern for the DIC analysis is also shown. The final shear strain at break cannot be measured due to data loss. The speckle patterns are fell off from the specimens before they are broken. Only valid shear strains are presented in Fig. 4(b). Table 2 summarizes the results obtained from the tension and shear tests.

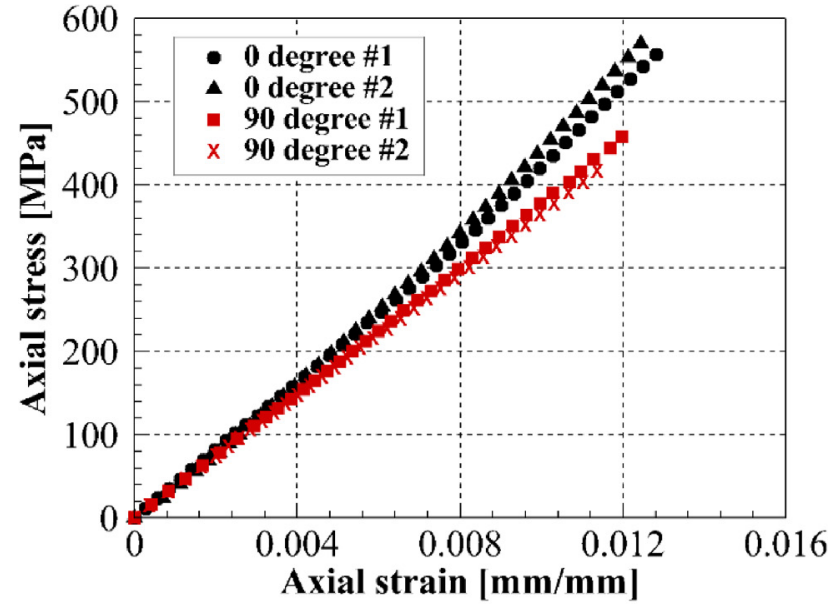

(a)

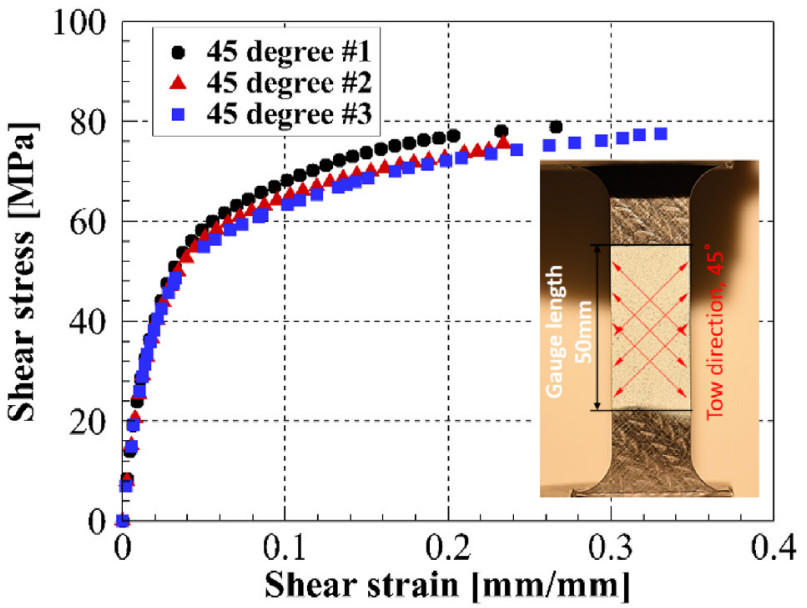

(b)

Fig. 4. Mechanical testing of the NCF composite specimens (a) Tension tests (b) Shear tests.

Table 2

Results obtained from tension and shear tests.

\begin{tabular}{llll}
\hline Orientation & Stiffness (GPa) & Strength (MPa) & Elongation at break (\%) \\
\hline 0-degree tension & $44.65 \pm 1.66$ & $569.12 \pm 5.35$ & $1.260 \pm 0.025$ \\
90-degree tension & $37.00 \pm 0.82$ & $444.74 \pm 15.16$ & $1.180 \pm 0.019$ \\
Shear & $1.45 \pm 0.03$ & $77.71 \pm 1.81$ & N/A \\
\hline
\end{tabular}

\section{Impact tests to determine the BVID energy}

Impact tests are carried out based on ASTM/D7136 to find the energy level that causes barely visible impact damage (BVID) on the

Table 1

ASTM/D3171 test results.

\begin{tabular}{|c|c|c|c|c|}
\hline & Specimen A & Specimen B & Specimen C & Average \\
\hline $\mathrm{V}_{\text {comp }}\left(\mathrm{mm}^{3}\right)$ & 1496.5 & 1497.5 & 1498.0 & 1497.0 \\
\hline $\mathrm{W}_{\text {comp }}(\mathrm{g})$ & 1.98 & 2.00 & 2.01 & 2.00 \\
\hline $\mathrm{W}_{\text {fiber }}(\mathrm{g})$ & 1.01 & 1.05 & 1.01 & 1.02 \\
\hline $\mathrm{W}_{\text {matrix }}(\mathrm{g})$ & 0.97 & 0.95 & 1.00 & 0.98 \\
\hline$\rho_{\text {comp }}\left(\mathrm{g} / \mathrm{cm}^{3}\right)$ & 1.323 & 1.336 & 1.342 & 1.334 \\
\hline $\mathrm{V}_{\text {fiber }}(\%)$ & 35.5 & 36.9 & 35.5 & 36.0 \\
\hline $\mathrm{V}_{\text {matrix }}(\%)$ & 58.9 & 57.7 & 60.7 & 59.1 \\
\hline $\mathrm{V}_{\text {void }}(\%)$ & 5.6 & 5.4 & 3.8 & 4.9 \\
\hline
\end{tabular}


NCF composite structure. The specimens are tested at various impact energies from $2 \mathrm{~J}$ to $12 \mathrm{~J}$ with the interval of $2 \mathrm{~J}$. Instron CEAST 9350 tester installed with the hemispherical impactor is used for the impact tests. Fig. 5 shows the setup for impact tests.

\subsection{Load-time history curves}

Fig. 6 shows typical load-time history curves obtained at various energy levels. A distinct load drop is observed from the impact energy of $4 \mathrm{~J}$ as indicated with the circle. The load-time history curves are significantly deteriorated as the impact energy increases. The first peaks on each curve are observed at earlier stages with the increase in the

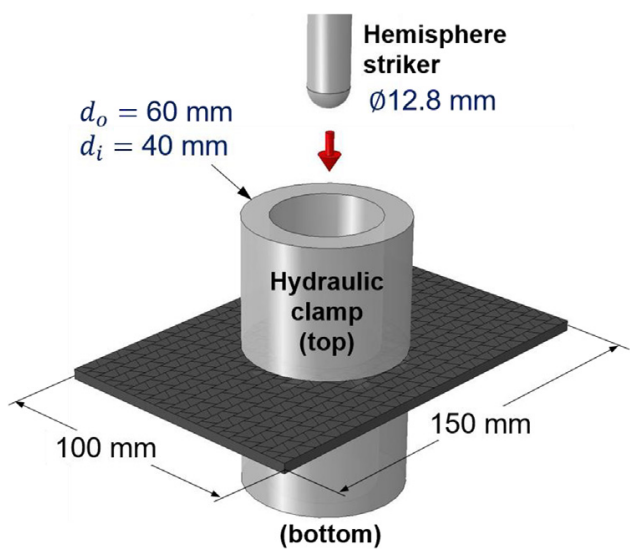

Fig. 5. Impact test setup. impact energy. The peaks or load-drops on the curves imply that significant damage has occurred in the composite specimens beyond the regime in which the material deforms as a continuum. The maximum loads measured at each energy level are plotted in Fig. 7. As can be seen in Fig. 7, beyond the 4-joule impact, the composite structure rapidly loses the energy absorption capability, again implying that the structure releases the impact energy through fracture processes. The failure patterns occurring inside the specimens at different energy levels will be discussed later.

\subsection{Damage and failure patterns}

Fig. 8 shows damage patterns induced at different impact energy levels. Circular indentations are observed on the impacted surfaces

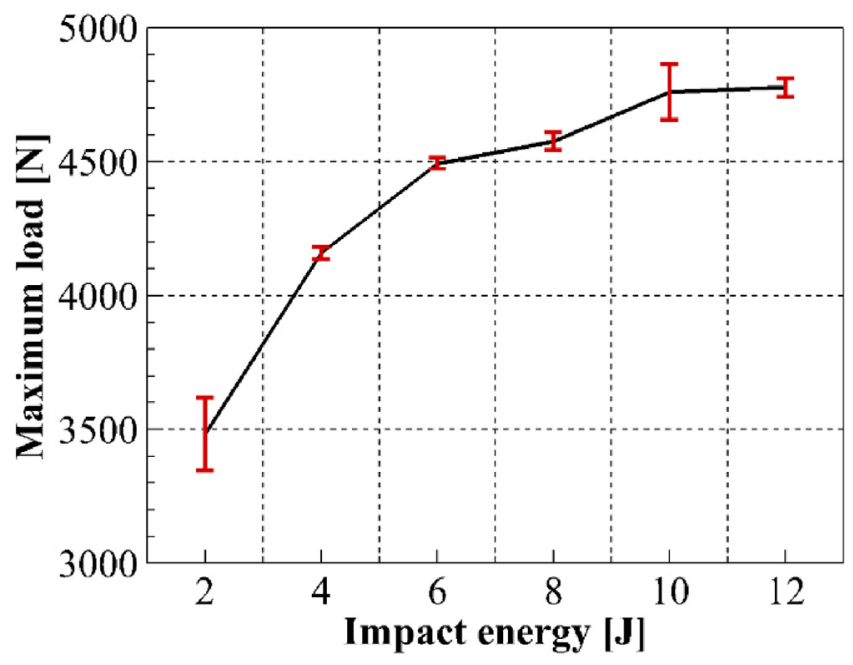

Fig. 7. Maximum loads at different impact energies.
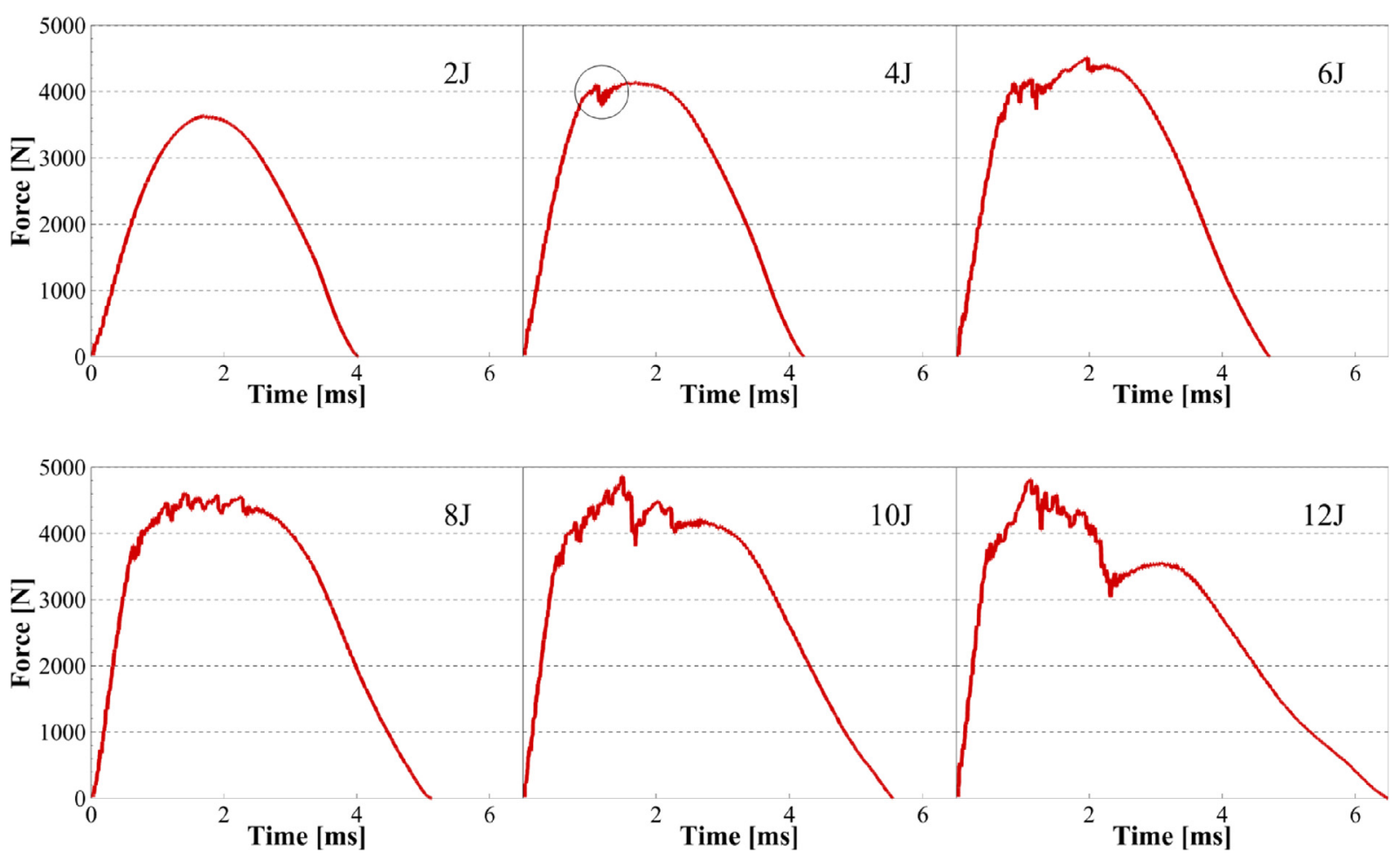

Fig. 6. Load-time history curves at various energy levels. 


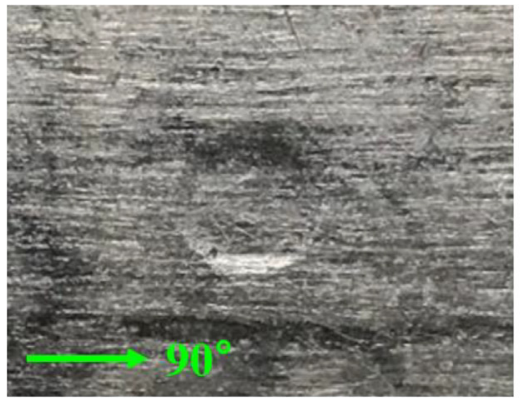

(a) 2 Joules

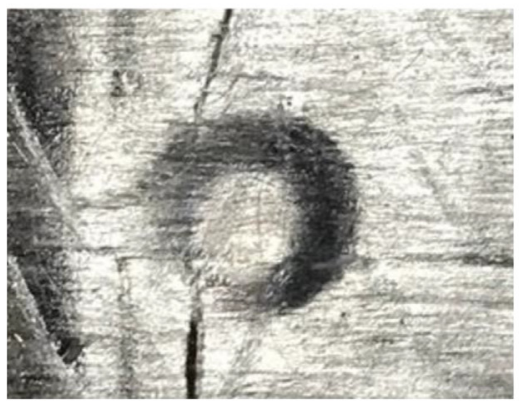

(d) 8 Joules

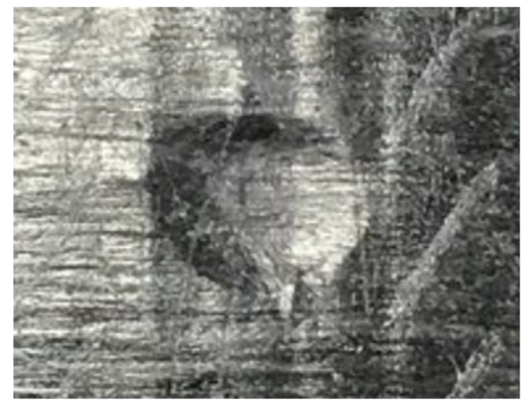

(b) 4 Joules

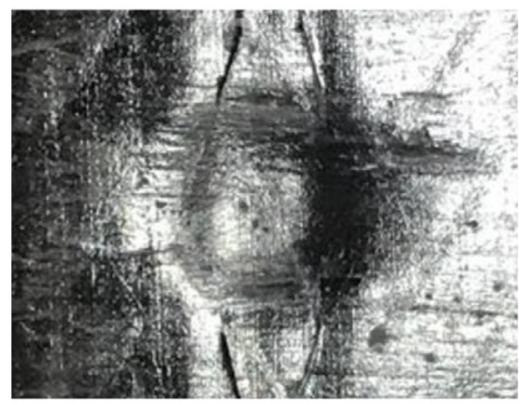

(e) 10 Joules

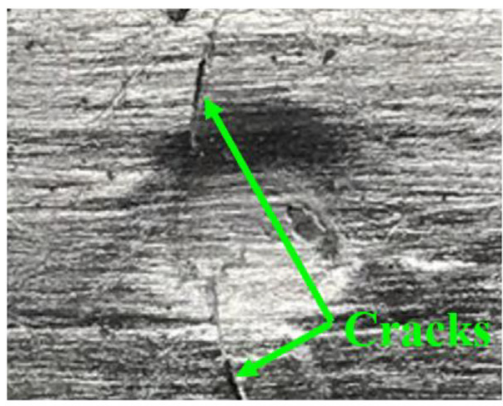

(c) 6 Joules

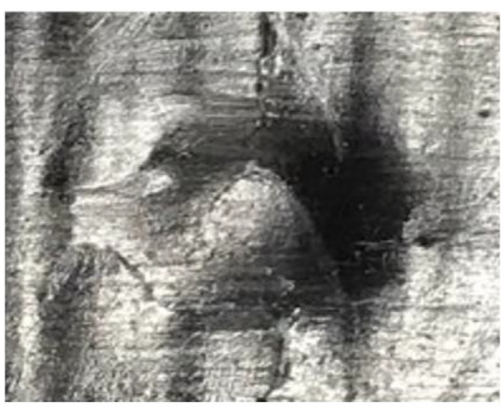

(f) 12 Joules

Fig. 8. Damage patterns on the impacted surfaces of the NCF specimens.

for all the energy levels. From the case of the impact energy of $6 \mathrm{~J}$, cracks are present around the indented areas as indicated in Fig. 8 (c). Internal fracture patterns are examined through X-ray computed tomography (CT) in Fig. 9. CT scanning is performed using SkyScan 1176 with the image resolution of $8.86 \mu \mathrm{m}$ per pixel. Projection images (radiographs) are obtained at every $0.3^{\circ}$ with the exposure time of $900 \mathrm{~ms}$. The voltage and current of the X-ray beam source are set to $40 \mathrm{keV}$ and $400 \mu \mathrm{A}$, respectively. Damaged specimens are first dipped in dye penetrant [29] before they are scanned. X-ray CT results are displayed in Fig. 9 when the impact energies are $4 \mathrm{~J}$ and $12 \mathrm{~J}$. At the impact energy of $4 \mathrm{~J}$, it is interesting to note that the impacted side is not fractured while relatively severe damage is found on the far side. This observation implies that, although the damage pattern found on the impacted surface is not fractured as shown in Fig. 8(b), significant failures have already occurred on the opposite side and inside the structure, which cannot be easily accessible for an eye inspection. The specimen impacted at $12 \mathrm{~J}$ exhibits multiple failures such as delaminations, transverse cracks, and fiber ruptures as shown in Fig. 9(b). The progression of the various failure modes are reflected as a severe fluctuation in the load-time history curve in Fig. 6(f). The damage extent on the far side of the impact point is larger than that of impacted side. Indeed, for both cases ( $4 \mathrm{~J}$ and $12 \mathrm{~J}$ ), damage areas increases from the impacted side to the far side, resulting in a typical "bell shape" [30].

The indentations in Fig. 8 are measured and the corresponding results are displayed in Fig. 10. While the maximum load in Fig. 7 gradually increases with the increasing impact energy, the indentation depth and diameter are continuously growing. Especially, they increase rapidly from the impact energy of $6 \mathrm{~J}$. The rapid growth may result from the cracks found on the specimen surfaces. In addition, the internal failures significantly deteriorate the elastic recovery capability of the specimens, leading to larger permanent deformation characterized by the indentation depth and diameter in the presented analysis. From the experimental observations and quantitative measurements, it can be concluded that 4-joule energy is the limit of the barely visible impact damage (BVID) for the NCF composite structure since the impact damage on the impacted side is comparatively small according to the observations in Fig. 8 but significant internal failures are detected on the far side as revealed in Fig. 9(a).

\section{Compression after impact strength test}

\subsection{Test setup}

Impacted specimens are tested to measure the compressive strength after impact. Fig. 11 shows the experimental setup for the compression test. Instron 5982, electromechanically driven loading frame, is used for the compression test at the loading rate of $5 \mathrm{~mm} / \mathrm{min}$. A damaged specimen is mounted in the fixture designed and fabricated according to ASTM/D7137. Two charge-couple device (CCD) cameras (Grasshopper3, FLIR Systems, Inc.) are placed as shown in Fig. 11 to perform three-dimensional (3D) digital image correlation (DIC) analysis. Each camera has 6-million-pixel resolution and is equipped with a Cmount lens having a focal length of $25 \mathrm{~mm}$ and a maximum aperture of f1.4. In the presented study, the aperture is set to f8 to achieve extended focus depth and thus observe a wide specimen area. Continuous lighting is provided from the two light-emitting diode (LED) lights to avoid diffuse reflection on the specked surface. In addition, metal fixture surfaces are covered with masking tapes to remove strong yet unnecessary light reflection. A commercial software package (ARAMIS 6.3, GOM GmbH, Germany) is employed to calibrate the cameras and compute displacement fields. The present 3D DIC setup results in 0.04 pixel resolution, which is very close to the theoretical maximum resolution of 0.02 pixel [31].

Fig. 12(a) shows a speckle pattern applied on the front surface for the DIC analysis. In general, after pictures are taken while a sample is being deformed, the DIC technique tracks the motions of speckles between images by utilizing grey level or intensity values [32]. If image contrast is inconsistent due to distorted reflection of light on a speckled surface, the accuracy of DIC results may be contaminated. In the presented study, white flat paint is first uniformly sprayed on an entire measurement area. Then, a speckle pattern is created by flick- 


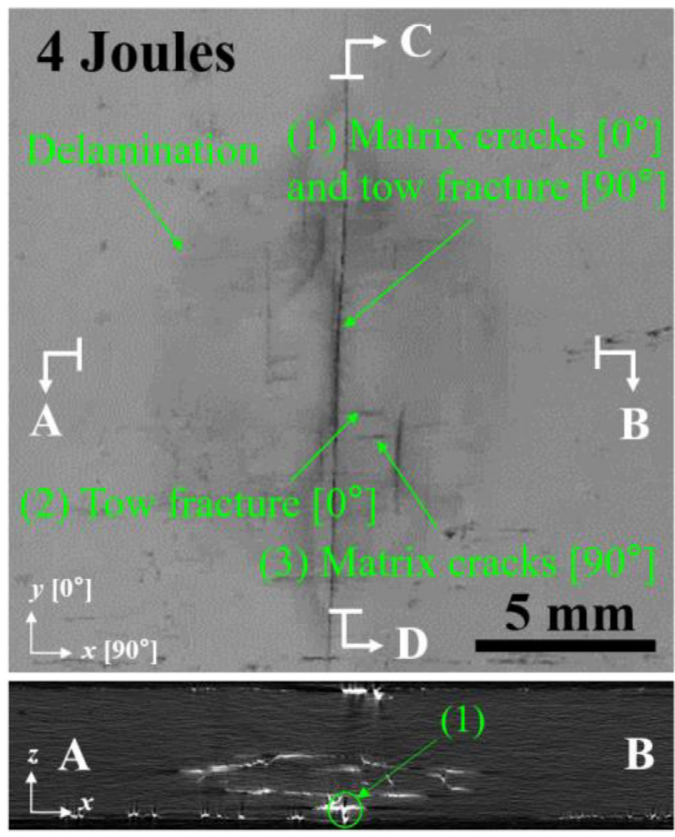

(a) 4 Joules

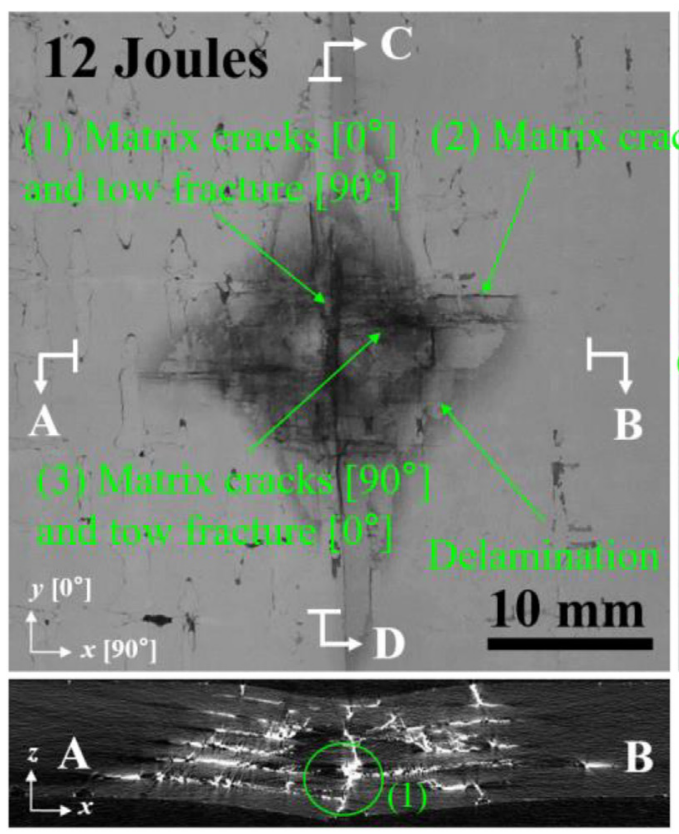

(b) 12 Joules

Fig. 9. X-ray computed tomography for internal damage patterns under the impact point.

ing a fine detail brush with black flat paint. In this manner, speckles that are bigger and more clear than spray dots can be obtained. As a result, image contrast is greatly improved and consistent between different images, leading to better correlation results between the two cameras. In addition to the speckle pattern, as shown in Fig. 12(b), strain gages are attached on the opposite side. The two strain gages are located at a distance of $l$ from the center of the impact area as illustrated in Fig. 12(b). For pristine panels, the distance is $5 \mathrm{~mm}$ from the center. Impacted specimens have larger distances due to the impact damage. For the panels impacted at $4 \mathrm{~J}$ and $8 \mathrm{~J}$, the distance is $6 \mathrm{~mm} . l=20 \mathrm{~mm}$ for the panels impacted at $20 \mathrm{~J}$.

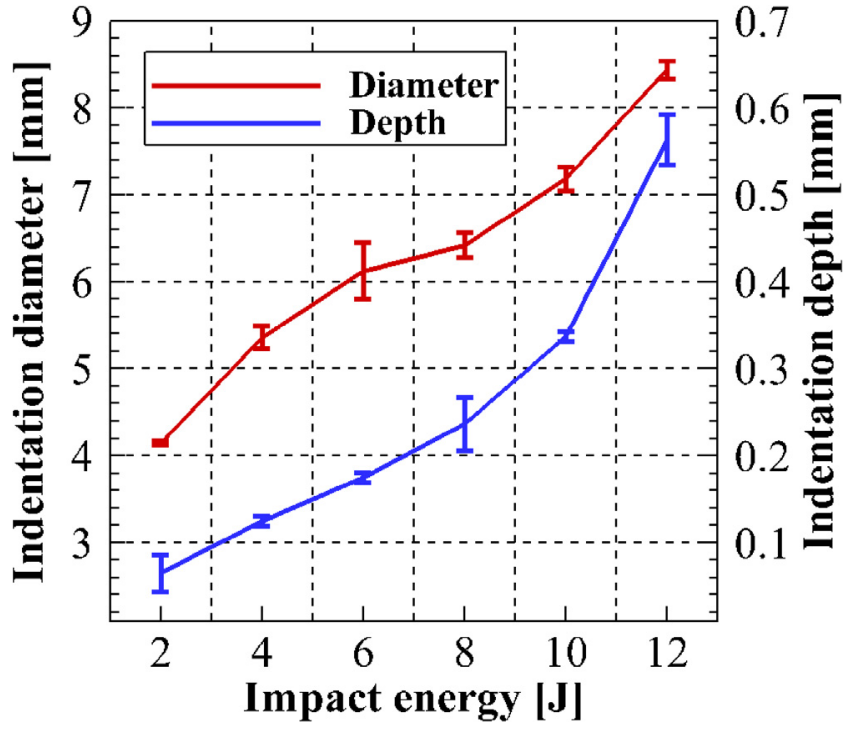

Fig. 10. Measurements of the indentation caused by the impact.

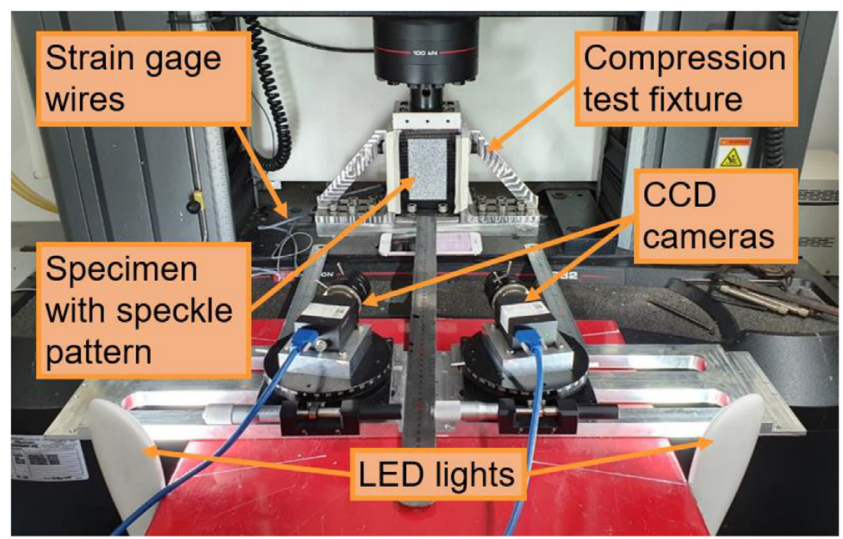

Fig. 11. Experimental setup for CSAI measurement.

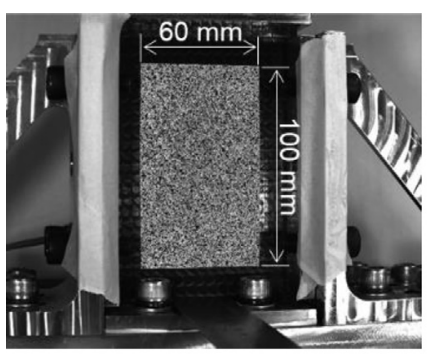

(a)

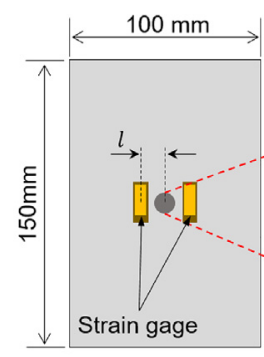

(b)
Fig. 12. (a) Speckle pattern on a front side of the specimen (b) Two strain gages attached near the indentation area.

\subsection{Results and discussion}

Fig. 13 shows the compression test results of a pristine panel and damaged specimens impacted at $4 \mathrm{~J}, 8 \mathrm{~J}$ and $12 \mathrm{~J}$. All the specimens are compressed along the 90-degree direction. As can be seen in Fig. 13, the compressive strengths are gradually reduced as the impact energy increases. Table 3 summarizes the compressive strengths after impact dependent on different energy levels. Beyond the impact 


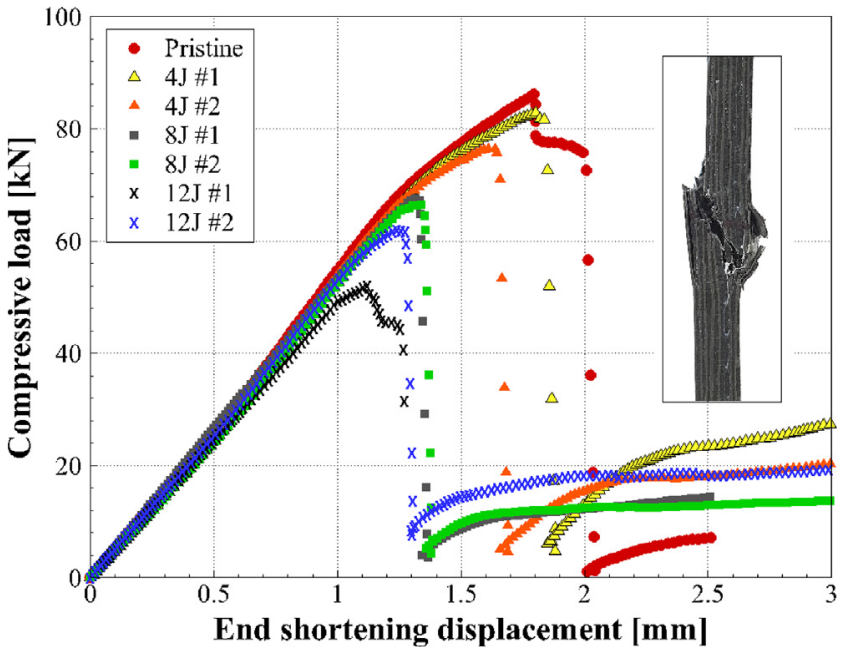

Fig. 13. Compressive responses of a pristine panel and damaged specimens impacted at $4 \mathrm{~J}, 8 \mathrm{~J}$ and $12 \mathrm{~J}$.

Table 3

Summary of the performances of the impacted panels.

\begin{tabular}{lll}
\hline Impact energy & Strength $(\mathrm{MPa})$ & Degradation rate* \\
\hline $4 \mathrm{~J} \mathrm{\# 1}$ & 215.3 & $6.38 \%$ \\
$4 \mathrm{~J} \mathrm{\# 2}$ & 194.3 & \\
Avg. & $204.8 \pm 14.9$ & $21.9 \%$ \\
$8 \mathrm{~J} \mathrm{\# 1}$ & 174.4 & \\
$8 \mathrm{~J} \mathrm{\# 2}$ & 167.0 & $32.8 \%$ \\
Avg. & $170.7 \pm 5.2$ & \\
$12 \mathrm{~J} \mathrm{\# 1}$ & 161.7 & \\
$12 \mathrm{~J} \mathrm{\# 2}$ & 132.4 & \\
Avg. & $147.0 \pm 20.7$ & \\
\hline
\end{tabular}

* Degradation rates are based on the strength value of the pristine panel.

energy of $4 \mathrm{~J}$, the compressive strengths reduce significantly. The compressive strengths are determined when the specimens fail by fiber breakage mainly caused by the formation of kink bands although their locations differ from specimens. Fig. 13 also shows a typical view of fiber-kinking failure. In the next sections, the compressive responses of each case are closely examined.

\subsubsection{Pristine panel}

Fig. 14 shows the load-displacement curve of the pristine specimen together with the axial and bending strains computed from the backto-back strain data obtained from DIC analysis and strain gages. The DIC analysis defines two virtual strain gages at the same locations of the physical strain gages attached on the opposite side as shown in Fig. 12(b). The DIC strain is averaged over the region of $5 \times 2 \mathrm{~mm}^{2}$, which is the same area of the foil strain gage. Back-toback strain gages are needed to decouple the axial and bending strains from the measured data. When the front and back strain data are available, the axial and bending strains can be obtained from

$\varepsilon_{\text {axial }}=\frac{\varepsilon_{\text {front }}+\varepsilon_{\text {back }}}{2}$

$\varepsilon_{\text {bending }}=\frac{\varepsilon_{\text {front }}-\varepsilon_{\text {back }}}{2}$

Here, $\varepsilon_{\text {front }}$ and $\varepsilon_{\text {back }}$ are the average strains between the measurements from the two side-by-side strain gages located on the same surface. As clearly seen in Fig. 14, the bending strain exhibits a sudden transition, implying the onset of global buckling. After the specimen buckles, the axial strain remains almost constant until the load reaches at its peak. Over the flat zone of the axial strain, a slight deterioration of the slope in the load curve is also observed.

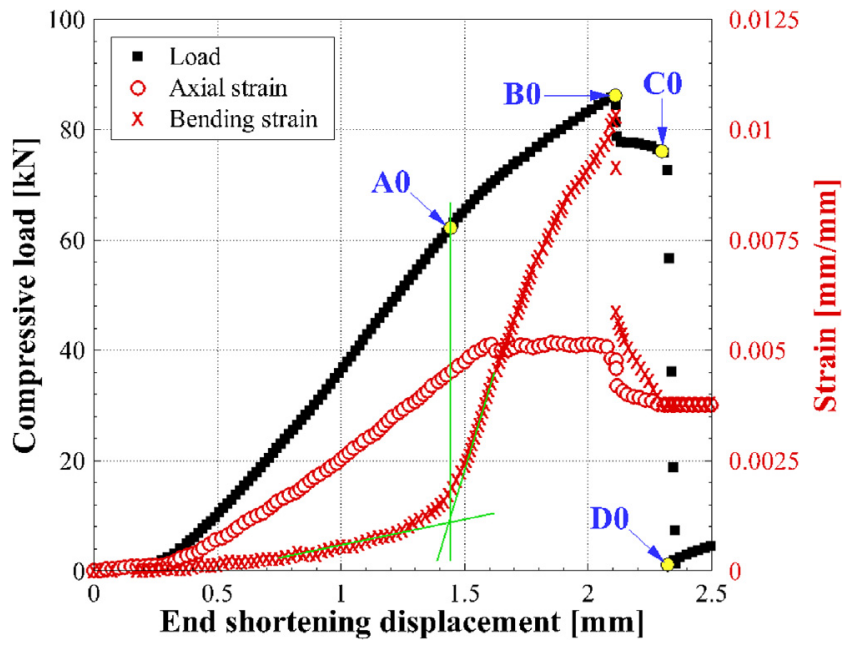

Fig. 14. Axial and bending strains of the pristine panel together with the compressive load.

The deformed configurations of the pristine panel computed from the DIC analysis at various loading stages are shown in Fig. 15. The loading stages A0, BO and CO in Fig. 15 are indicated in Fig. 14. Fig. 15(d) shows the failed specimen at the stage D0. As shown in Fig. 15(a), the panel clearly exhibits the first buckling mode. Fig. 15 (b) shows the increased out-of-plane deflection at the peak load. In Fig. 15(c), the location of the maximum deflection is shifted after the specimen fails at its first peak load. At the loading stage B0, the kink band is formed outside the speckled area as can be seen in Fig. 15(d). More specifically, the failure is found in the unclamped area between the top grip and knife edges of the CSAI test fixture.

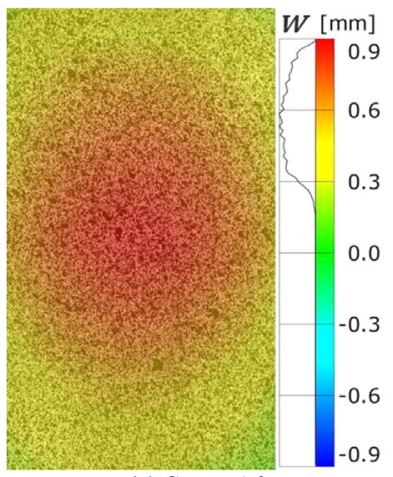

(a) Stage A0

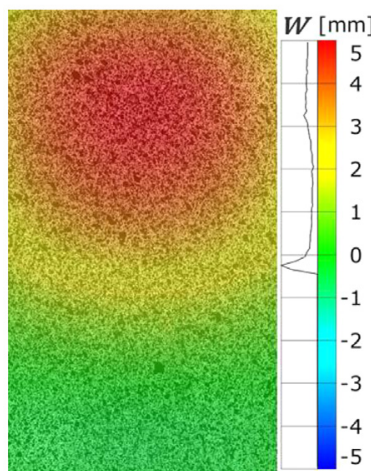

(c) Stage $\mathrm{C} 0$

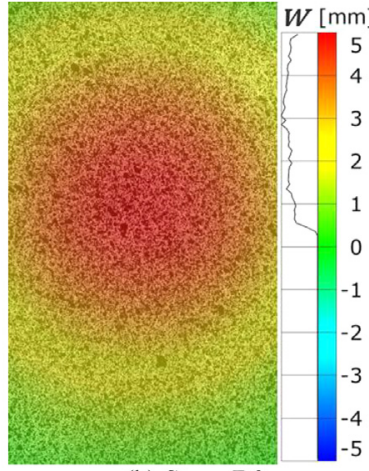

(b) Stage B0

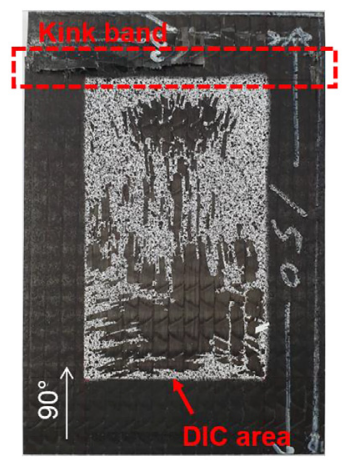

(d) Stage D0
Fig. 15. Out-of-plane deflections of the pristine plate at the loading stages indicated in Fig. 14. 
Stresses may be concentrated significantly in the open space between the clamps, leading to the failure in the unclamped space and the sudden shift in the location of the maximum deflection between $\mathrm{B} 0$ and C0.

The compressive response of the pristine panel is also studied using finite element analysis (FEA). Fig. 16(a) illustrates the finite element (FE) model of the plate with boundary and loading conditions. The plate model, having the size of $150 \mathrm{~mm} \times 100 \mathrm{~mm}$, is meshed with a sufficient number of shell elements. Two sides of the FE model are simply supported while the bottom edge is fully clamped. The top edge is also clamped but free to move in the loading direction. Elastic properties in Table 2 are used for the FE plate model. A compressive stiffness obtained from the load-displacement curve in Fig. 13 is used for the 90-degree direction. Buckling analysis is first performed and the first and second buckling modes are obtained as shown in Fig. 16(b) and (c). The compressive response of the plate is simulated using the arc-length method [33]. Displacement-controlled loading is applied on the top edge. In order to investigate the effect of geometric imperfections on the response, the first buckling mode is used for the initial configuration of the plate. The finite element analysis is performed using a commercial FE software package, ABAQUS.

Compressive responses of the crooked plate with three different initial maximum deflections are computed. The maximum initial deflection is characterized as a percentage of the plate thickness, which is $3.97 \mathrm{~mm}$. The computational results are presented in Fig. 17 using the compressive force as a function of the maximum out-of-plane deformation measured from the initial imperfect deflection. Experi-

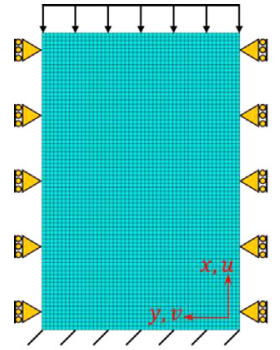

(a)
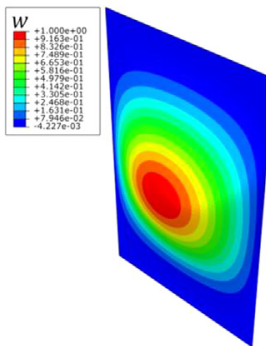

(b)

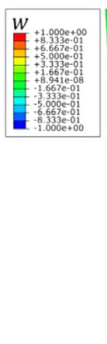

(c)
Fig. 16. (a) Finite element model of the pristine panel (b) First buckling mode (c) Second buckling mode.

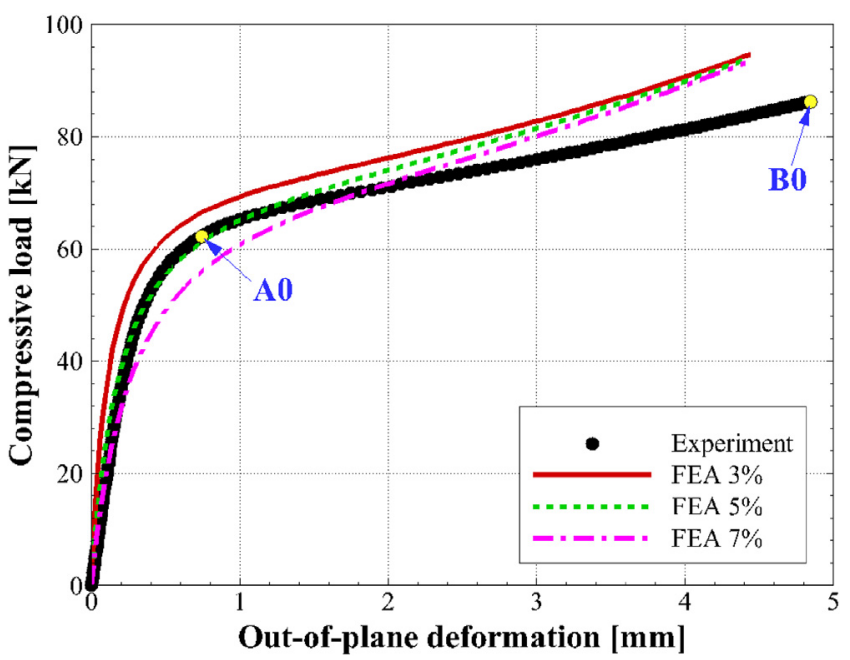

Fig. 17. Load versus maximum out-of-plane deformation of the pristine plate. mental results are also given in Fig. 17. For the experimental data, the compressive force is measured from the load cell and the deformation is computed from the 3D DIC analysis by averaging out-of-plane displacements over an area of $10 \times 10 \mathrm{~mm}^{2}$ that is centered at the location of the maximum displacement at the peak load. In Fig. 17, sudden transitioning responses, similar to bifurcation buckling behavior, are clearly observed from all the numerical and experimental results. It can be easily expected that the transitioning response approaches a theoretical bifurcation curve as the initial maximum deflection is vanishing. Before the transition occurs, the panel exhibits very steep behavior. However, in the post-buckling regime, the structure quickly loses its global stability. The maximum deflection increases much more rapidly than the compressive load. In the compression test, the loss of the global stability causes irrecoverable fracture processes as observed in Fig. 14. This can also explain softer response of the actual plate than the FEA results after the global buckling occurs. Neither fracture nor damage mechanics model is considered in the present FEA. However, it should be noted that the $5 \% \mathrm{FE}$ model successfully reproduces the pre-buckling and some extent of post buckling responses of the tested specimens.

\subsubsection{Damaged specimen at $4 \mathrm{~J}$}

Fig. 18 shows the axial and bending strains as the applied load increases as a function of the end-shortening displacement. The axial and bending strains are computed again using Eqs. (1) and (2). Front and back strains in Eqs. (1) and (2) are averaged between the sideto-side strain gages adjacent to the impact point. As can be expected, in Fig. 18, the axial strain is continuously increasing as the specimen is being compressed. However, the axial strain curve changes its direction following the sudden transition in the bending strain. The deformed configuration of the plate corresponding to the transition stage is shown in Fig. 19(a). Fig. 19(b) is associated with the peak of the axial strain. At the peak load, just before the specimen completely loses its load-carrying capability, the 2nd buckling mode is detected from the 3D DIC analysis as shown in Fig. 19(c). The decline of the bending strains observed in Fig. 18 may result from the 2nd buckling mode in which the middle of the plate becomes flat (see Fig. 16(c)). Note that the strains in Fig. 18 are measured near the impact point located in the middle of the plate.

It is interesting to note that, for this particular energy level, the 2nd buckling mode is consistently observed from all the tested specimens. Fig. 20 shows the typical buckling response of the specimens expressed using the compressive load and out-of-plane deflections at the two

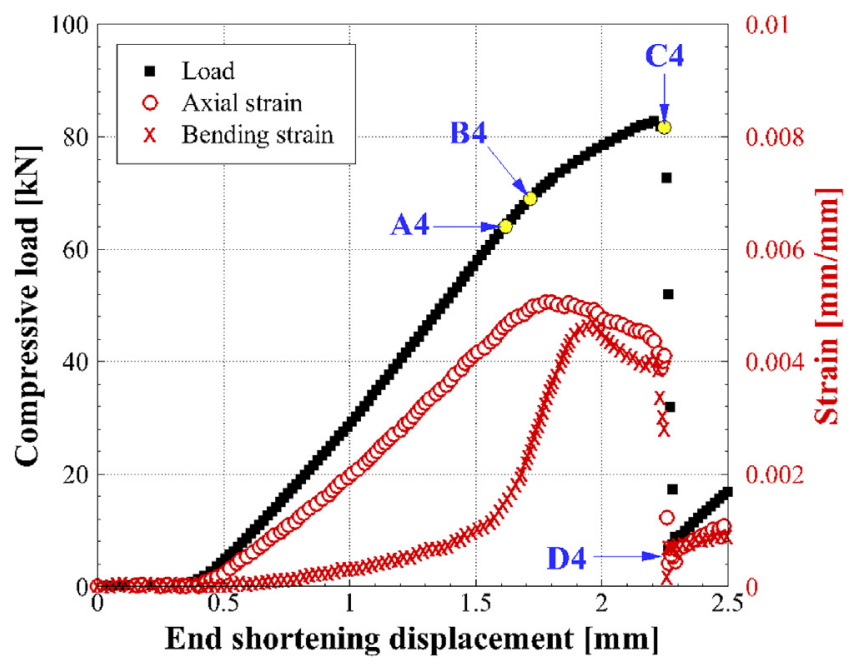

Fig. 18. Axial and bending strains with the load data of the specimen impacted at $4 \mathrm{~J}$. 


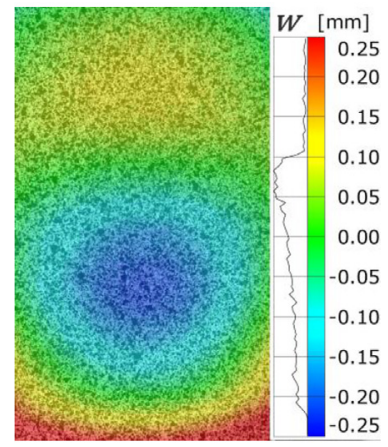

(a) Stage A4

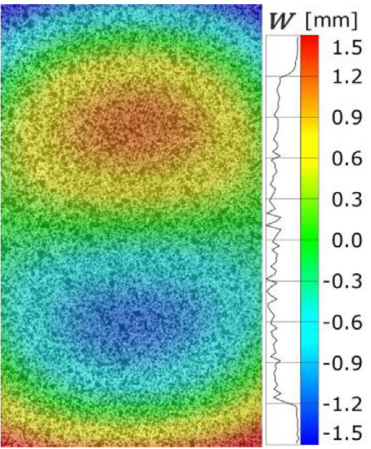

(c) Stage C4

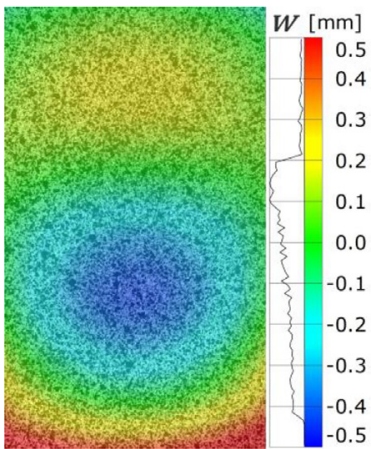

(b) Stage B4

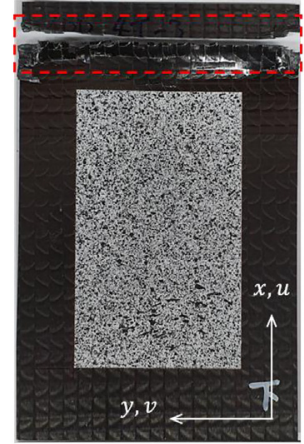

(d) Stage D4
Fig. 19. Deformed configurations of the compressed plate at various loading stages.

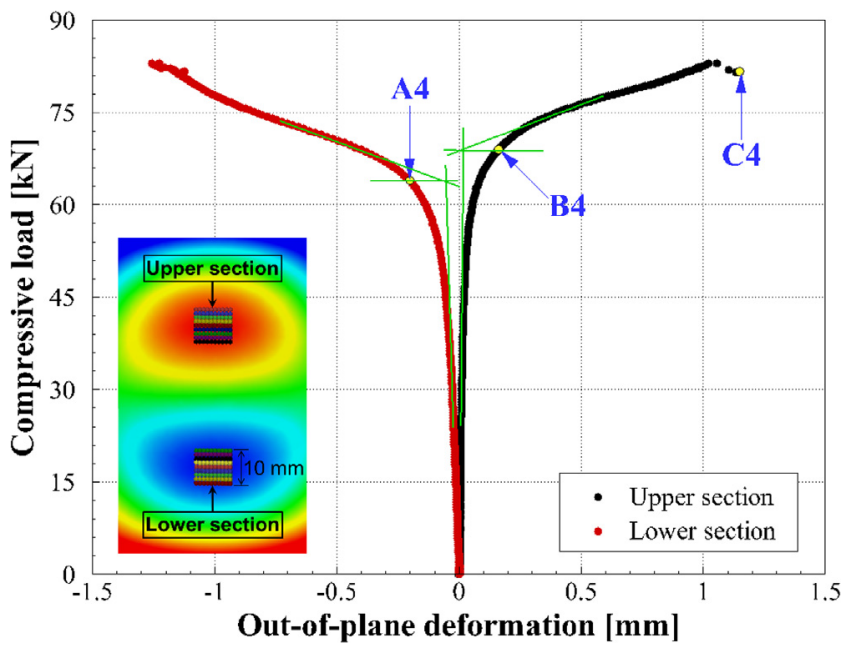

Fig. 20. Out-of-plane deflections at the two peak locations with a variance of the compressive load.

peak locations. The out-of-plane deformations of the upper and lower sections are averaged over the $10 \mathrm{~mm} \times 10 \mathrm{~mm}$ areas centered at the two peak as indicated in Fig. 20. As shown in Fig. 20, the pre-buckling responses are very steep as in the case of the pristine panel in Fig. 17. The lower section buckles first and the upper part immediately follows. The displacement fields corresponding to the two buckling events are given in Fig. 19(a) and (b), respectively. FEA predicts that the theoretical buckling loads associated with the 1st and 2nd modes are $68.7 \mathrm{kN}$ and $73.7 \mathrm{kN}$, respectively. The buckling loads measured from the experimental curves in Fig. 20 are $64.0 \mathrm{kN}$ and $69.0 \mathrm{kN}$ for the lower and upper sections, respectively. The measured buckling loads are much lower than the theoretical critical buckling load although the experimental loads are associated with the 2nd buckling mode. The discrepancy may result from the internal damage and initial crookedness of the impacted specimens.

\subsubsection{Damaged specimens at 8 and $12 \mathrm{~J}$}

Specimens impacted at $8 \mathrm{~J}$ and $12 \mathrm{~J}$ exhibit very similar compressive response and thus only the test results corresponding to $12 \mathrm{~J}$ are presented here. Fig. 21 shows the compressive response of the WCM panel impacted at $12 \mathrm{~J}$. The axial and bending strains are computed from the back-to-back strain data obtained from virtual and physical strain gages. Fig. 22(a) shows the virtual strain gages that are located at a distance of $20 \mathrm{~mm}$ from the impact point. As shown in Fig. 21, the axial strain rapidly increases at first while the bending strain is negligibly small. Near-zero bending strains imply that the straightness and alignment of the specimen are almost perfect. As the load increases further, the bending strain starts suddenly increasing at the loading stage B12, which is related to the peak of the axial strain. The bending strain keeps increasing until the specimen collapses at its peak load.

DIC results associated with the interesting points marked along the load curve in Fig. 21 are given in Fig. 22. Note that Fig. 22(a) shows the undeformed configuration of the damaged panel with the $z$ coordinates. The indentation depth and area are clearly visualized through the present 3D DIC analysis. The indent depth or the minimum z-coordinate measured from the 3D DIC technique is almost identical to the measurement in Fig. 10. When the rapid growth of the bending strain starts at B12 in Fig. 21, the panel deforms into a shape of the 2nd buckling mode as shown in Fig. 22(b). However, at the peak load, the first buckling mode is dominantly observed in Fig. 22(c) although the maximum deflection is not located exactly in the middle of the plate. In fact, the location of the maximum deflection in Fig. 22 (c) conforms to the impact point in Fig. 22(a). The excessive bending deformation results in the catastrophic failure as shown in Fig. 22(d). Fig. 23 plots the out-of-plane displacement along the pathline at different loading stages. The vertical pathline crosses the location of the maximum deflection associated with the peak load. Between the two adjacent loading stages B12 and C12, a significant bending deformation is observed from Fig. 23. The kink band region, in which DIC fails as shown in Fig. 22(d), is also shadowed in Fig. 23. The failure envelope is closely linked to the location of the maximum deflection.

The specimens impacted at $8 \mathrm{~J}$ also exhibit similar compressive responses. They first deform into the 2nd buckling mode, but the deformed shapes eventually transform into the 1st buckling mode. The location of the maximum deflection at their peak loads again coincides with the impact point. This coincidence results from more extensive damage underneath the impact point. Recall that the failure

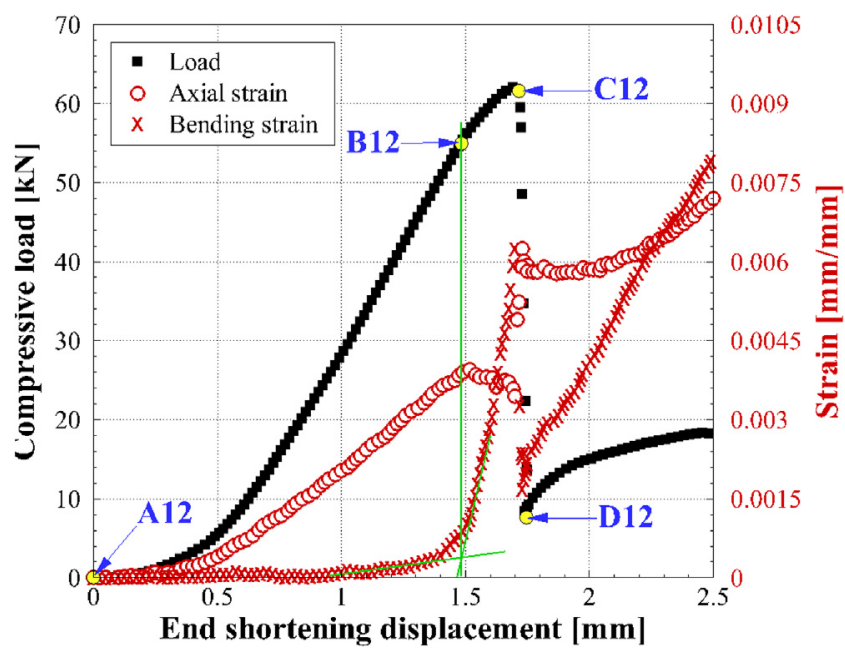

Fig. 21. Compressive responses of the impacted panel at $12 \mathrm{~J}$. 


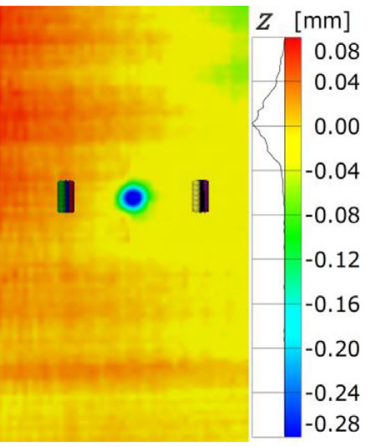

(a) Stage A12

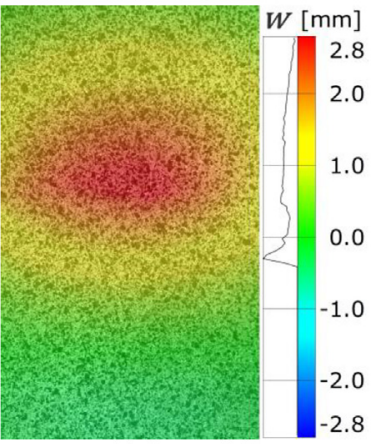

(c) Stage C12

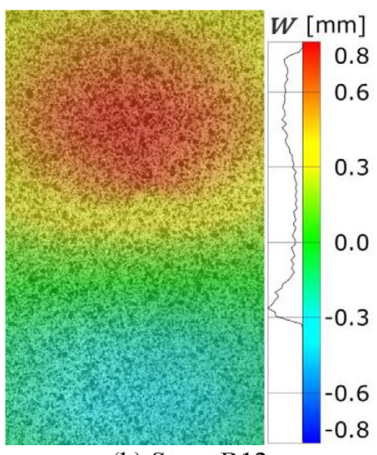

(b) Stage B12

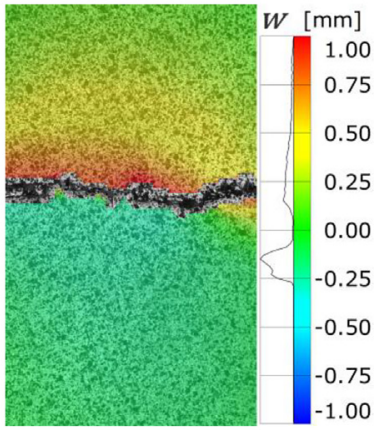

(d) Stage D12
Fig. 22. Deformed configurations of the compressed plate at various loading stages.

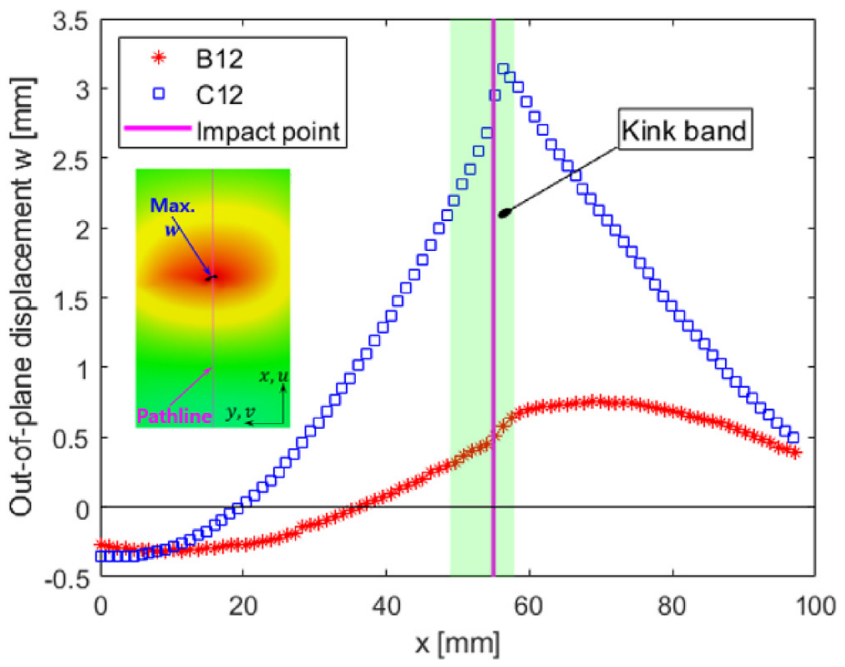

Fig. 23. Deformed configurations of the compressed plate at various loading stages.

location of the 4-joule specimen does not conform to the impact point. The damage extent of the 4-joule specimen is much less than those of the specimens impacted at higher energy levels as examined in Fig. 9.

\section{Conclusions}

CSAI study on the NCF composite structures manufactured through the wet compression molding process is presented. The composite plates are first impacted at various impact energy levels and detailed post-mortem examinations on the damaged specimens are followed. $\mathrm{X}$-ray CT images reveal the typical bell-shape damage shape, which is instrumental to determine the BVID limit of the composite structures. Compression tests are performed on the impacted panels to eval- uate the structural integrity. 3D DIC technique is employed in the CSAI experiments and buckling-induced failure responses of the plates are clearly visualized. Less than $10 \%$ reduction in the compressive strength is measured for the plate impacted at the BVID energy. Considering the mechanical performance with the low void content, the WCM product may be used as a major load-bearing structure if the fiber volume fraction can be further improved.

\section{Data availability}

The raw/processed data required to reproduce these findings cannot be shared at this time due to technical or time limitations.

\section{Declaration of Competing Interest}

The authors declare that they have no known competing financial interests or personal relationships that could have appeared to influence the work reported in this paper.

\section{Acknowledgement}

This research was supported by the Korea Evaluation Institute of Industrial Technology (KEIT) with the granted financial resource from the Ministry of Trade, Industry and Energy (MOTIE), Republic of Korea (Grant No.: R004077). The authors are also grateful for the financial support from Ulsan National Institute of Science and Technology (UNIST) through the 2020 Research Fund (Grant No.: 1.200031.01).

\section{References}

[1] Henning F, Karger L, Dorr D, Schirmaier FJ, Seuffert J, Bernath A. Fast processing and continuous simulation of automotive structural composite components. Compos Sci Technol 2019;171:261-79.

[2] Deloitte Touche Tohmatsu Limited, Automotive and composite materials: current state and forecast, JEC Composites Publication, Paris, France; 2018.

[3] Chaudhari R, Rosenberg P, Karcher M, Schmidhuber S, Elsner P, Henning F. High pressure RTM process variants for manufacturing of carbon fiber reinforced composites. In: 19th International Conference on Composite Materials, Montreal, Canada, 28 July to 2 August 2013.

[4] Akif Yalcinkaya M, Murat Sozer E, Cengiz Altan M. Fabrication of high quality composite laminates by pressurized and heated-VARTM. Compos A Appl Sci Manuf 2017;102:334-46.

[5] Li Y, Lin Z, Jiang A, Chen G. Experimental study of glass-fiber mat thermoplastic material impact properties and lightweight automobile body analysis. Mater Des 2004;25(7):579-85.

[6] Feraboli P, Peitso E, Deleo F, Cleveland T, Stickler P. Characterization of prepregbased discontinuous carbon fiber/epoxy systems. J Reinf Plast Compos 2009;28 (10):1191-214

[7] Bergmann J, Dormann H, Lange R. Interpreting process data of wet pressing process. Part 1: Theoretical approach. J Compos Mater 2016;50(17):2399-407.

[8] Bergmann J, Dormann H, Lange R. Interpreting process data of wet pressing process. Part 2: verification with real values. J Compos Mater 2016;50 (17):2409-19.

[9] Barkoula N, Garkhail S, Peijs T. Effect of compounding and injection molding on the mechanical properties of flax fiber polypropylene composites. J Reinf Plast Compos 2010;29(9):1366-85.

[10] Law T, Phua Y, Senawi R, Hassan A, Mohd Ishak Z. Experimental analysis and theoretical modeling of the mechanical behavior of short glass fiber and short carbon fiber reinforced polycarbonate hybrid composites. Polym Compos 2014;37 (4).

[11] Liu S, Chen Y. The manufacturing of thermoplastic composite parts by waterassisted injection-molding technology. Compos A Appl Sci Manuf 2004;35 (2):171-80.

[12] Al-Qureshi H. Automobile leaf springs from composite materials. J Mater Process Technol 2001;118:58-61.

[13] Kong C, Lee H, Park H. Design and manufacturing of automobile hood using natural composite structure. Compos Part B 2016;91:18-26.

[14] Liu Z, Lu J, Zhu P. Lightweight design of automotive composite bumper system using modified particle swarm optimizer. Compos Struct 2016;140:630-43.

[15] Ball C, Greydanus S, Swentek I, Nara K. Development of an epoxy carbon fiber reinforced roof frame using the high pressure resin transfer molding (HP-RTM) process, SAE Technical Paper 2020-01-0773; 2020.

[16] Baskaran M, Ortiz de Mendibil I, Sarrionandia M, Aurrekoetxea J, Acosta J, Argarate U, Chico D. Manufacturing cost comparison of RTM, HP-RTM and CRTM for an automotive roof. In: 16th European Conference on Composite Materials, Seville, Spain, 22-26 June 2014. 
[17] Bartus S, Vaidya UK, Ulven CA. Design and development of a long fiber thermoplastic bus seat. J Thermoplast Compos Mater 2006;19(2):131-54.

[18] Erica R, Frank R, Richard R, Randolph E. Strategic materials selection in the automobile body: economic opportunities for polymer composite design. Compos Sci Technol 2008;68:1989-2002.

[19] Starke J. Carbon composites in automotive structural applications. EuCIA: Compos Sustainability, 19 March 2016, Brussels. http://www.eucia.eu/userfiles/files/ Starke-Eucia\%202016-V4-Druck\%20b.pdf

[20] Ilcewicz LB, Smith PJ, Hanson C, Walker T, Metschan T, Mabson G, Willden K, Flynn B, Scholz D, Polland D, Fredrikson H, Olson J, Backman B. Advanced technology composite fuselage - program overview. NASA CR4734;1997.

[21] Fial J, Harr M. Automated wet compression moulding of load-path optimized TFP preforms with low cycle times. In: IOP Conference Series: Materials Science and Engineering, vol. 406, 13th International Conference on Textile Composites, Milan, Italy, 17-19 September 2018.

[22] Swentek I, Beck B, Potyra T, Ugresic V, Henning, F. Impact of HP-RTM process parameters on mechanical properties using epoxy and polyurethane. In: Proceedings of Composite and Advanced Materials Expo., Dallas, Texas, USA, 26-29 October 2015;1953-64.

[23] Behnisch F, Rosenberg PA, Weidenmann K, Henning F. Investigation of the matrix influence on the laminate properties of epoxy-and polyurethane-based CFRPs manufactured with HP-RTM-process. In: Proceedings of 32th International Conference of the Polymer Processing Society, Lyon, France, 25-29 July 2016, vol. 1914(1);2016: 180003.
[24] Bodaghi M, Cristóvão C, Gomes R, Correia NC. Experimental characterization of voids in high fibre volume fraction composites processed by high injection pressure RTM. Compos A Appl Sci Manuf 2016;82:88-99.

[25] Rondina F, Taddia S, Mazzocchetti L, Donati L, Minak G, Rosenberg P, et al. Development of full carbon wheels for sport cars with high-volume technology. Compos Struct 2018;192:368-78.

[26] Cherniaev A, Zeng Y, Cronin D, Montesano J. Quasi-static and dynamic characterization of unidirectional non-crimp carbon fiber fabric composites processed by HP-RTM. Polym Test 2019;76:365-75.

[27] Bockelmann, P. Process control in compression molding of composites. Doctoral dissertation, Technische Universität München, Munich, Germany; 2017.

[28] Mariano F. Development of an LCM process for rapid curing CFRP parts. Doctoral dissertation, Politecnico di Torino, Turin, Italy; 2019.

[29] Hong C, Ji W. Complementary ex situ investigation of various fracture modes in a single-edge-notched symmetric cross-ply laminate subjected to tensile loading. Compos Commun 2020;17:28-31.

[30] Davis GAO, Olsson R. Impact on composite structures. Aeronaut J 2004;108 (1089):541-63.

[31] GOM GmbH, ARAMIS v6.3 User Manual. Germany; 2005.

[32] Lee S, Ji W. DVC analysis of a polymer material subjected to tensile loading with synchrotron radiation tomography. Polym Test 2020;81:106204.

[33] Riks E. An incremental approach to the solution of snapping and buckling problems. Int J Solids Struct 1979;15(7):529-51. 